\title{
Work in Progress: Incorporating interactive modules related to cell culture and plasmid design into introduction to biomedical engineering
}

\section{Dr. Rosalyn Delia Abbott, Carnegie Mellon University}

Rosalyn Abbott is an Assistant Professor in Biomedical Engineering with a courtesy appointment in Materials Science and Engineering. Professor Abbott received her B.S. and M.S. degrees in Biomedical Engineering from Rensselaer Polytechnic Institute and her Ph.D. degree in Bioengineering from the University of Vermont. She was subsequently a postdoctoral fellow in the Biomedical Engineering Department at Tufts University working under the supervision of Professor David Kaplan, where she developed adipose tissue engineered models. Her lab at CMU focuses on using tissue engineering to study metabolic dysregulation during the complex transition of obesity to insulin resistant type II diabetes.

\section{Dr. Conrad M Zapanta, Carnegie Mellon University}

Conrad M. Zapanta is the Associate Department Head of Education and a Teaching Professor in the Department of Biomedical Engineering at Carnegie Mellon University in Pittsburgh, PA. Dr. Zapanta received his Ph.D. in Bioengineering from the Pennsylvania State University in University Park, PA, and his B.S. in Mechanical Engineering (with an option in Biomedical Engineering) from Carnegie Mellon University. Dr. Zapanta has served as a Visiting Assistant Professor of Engineering at Hope College in Holland, MI, an Adjunct Professor of Engineering at Austin Community College in Austin, TX, and an Assistant Professor of Surgery and Bioengineering at The Pennsylvania State University in Hershey, PA. He also worked for CarboMedics Inc. in Austin, TX, in the research and development of prosthetic heart valves.

Dr. Zapanta's primary teaching responsibilities are Biomedical Engineering Laboratory and Design. Additional teaching interests include medical device design education and professional issues in biomedical engineering. Dr. Zapanta's research interests are in developing medical devices to treat cardiovascular disease, focusing on the areas of cardiac assist devices and prosthetic heart valves.

Dr. Zapanta is an active member in the American Society for Artificial Internal Organs, American Society of Mechanical Engineers, the American Society for Engineering Education, and the Biomedical Engineering Society. He is a reviewer for several biomedical engineering journals. Dr. Zapanta also serves as a reviewer for the National Institutes of Health (NIH), Cardiovascular Sciences Small Business Special Emphasis Panel and as an ABET Program Evaluator (PEV) for Bioengineering and Biomedical Engineering programs.

\section{Dr. Michael Cameron Melville, Carnegie Mellon University}

Michael Melville works as a Data Science Research Associate at Carnegie Mellon University's Eberly Center for Teaching Excellence and Educational Innovation, where he consults with faculty, graduate students, and post-docs to design, implement, and assess research projects that relate to teaching and learning in their classrooms. He also contributes to a variety of program-level assessment projects on the CMU campus. Mike's training includes an M.A. and Ph.D. in Social Psychology from the University of New Hampshire, as well as an M.Ed. in sport and performance psychology from Springfield College. His interests include the science of learning, research methodology, and data analysis. Prior to joining the Eberly Center in 2017, Mike worked as the Teaching and Learning Research Coordinator at the Center for Excellence and Innovation in Teaching and Learning at the University of New Hampshire.

\section{Steven Moore, Carnegie Mellon University, HCII}


Work in Progress: Incorporating interactive modules related to cell culture and plasmid design into introduction to biomedical engineering

Rosalyn Abbott, ${ }^{1}$ Sophie Le Blanc, ${ }^{2}$ Michael Melville, ${ }^{2}$ Steven Moore, ${ }^{3}$ Conrad Zapanta ${ }^{1}$

Carnegie Mellon University: 1. Biomedical Engineering, 2. Eberly Center, 3. Human-Computer Interaction Institute

Introduction: The goal of this project was to determine if active learning would improve comprehension of 2 key concepts in "Introduction to Biomedical Engineering (BME)" class. The freshman-level core undergraduate course provides a broad overview of the field of BME and is intended to be taken first in the BME curriculum. Active learning is commonly defined as a method that engages students in the learning process through meaningful activities that require the student to think about what they are doing ${ }^{1}$. This is in contrast to passive learning where students passively receive information from the instructor usually through lectures. ${ }^{1}$ Active learning was pursued for the following studies as it is enjoyable, ${ }^{2}$ motivating to students (particularly underachieving students ${ }^{3,4}$ ), and increases confidence in the course material. ${ }^{5}$

The field of genetic engineering is an emerging and exciting area of BME research. The basis of this field is the design of recombinant DNA through plasmids ${ }^{6}$ (Pubmed Central has $\sim 100,000$ research articles on plasmid genetic engineering). Cell culture and plasmid design are included as exciting areas of cellular and molecular biotechnology in the Intro to BME class, however feedback from the students indicated that learning about these concepts in a lecture format was confusing and too theoretical in prior iterations of the class. Therefore, the main objective of this work-in-progress project was to improve comprehension of these 2 key BME techniques (cell culture and plasmid design). To do this, modules were added to increase the interaction with the material, providing an opportunity for students to visualize the process. These modules were designed to provide scaffolding for when students transfect cells and perform cell culture experiments in BME lab (a sophomore level class they take if they chose BME as a major). In prior iterations of this class, only a lecture covered this material. For this iteration the same lecture was given, followed by the interactive modules (all in the same 2 hour class).

\section{Learning objectives:}

- Identify and summarize key components required to perform cell culture experiments.

- Describe the functions of various parts of a plasmid.

- Describe the key steps in protein production using recombinant DNA technology.

The hypothesis was that interactive modules would enhance comprehension of cell culture and plasmid design concepts.

Methods: During a class period students performed virtual cell culture experiments in a computer lab. This was done through an online game from ThermoFisher Scientific (through Labster) that introduces students to the cell culture environment (Figure 1). The students play a video game where they make cell culture media, look at mammalian cell morphology under a microscope, learn aseptic technique, thaw frozen cells, learn what biological contamination looks like, calculate cell growth with doubling time, learn cell passaging and counting, and cryopreservation.

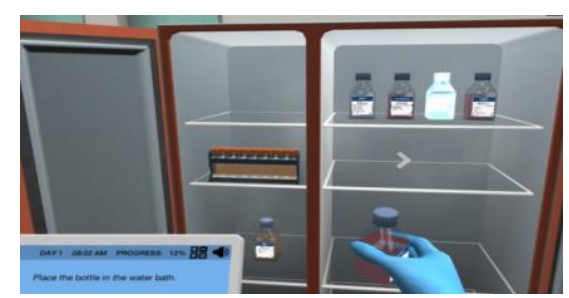

Figure 1. Screenshot of the cell culture game available through ThermoFisher Scientific (a Labster game). 

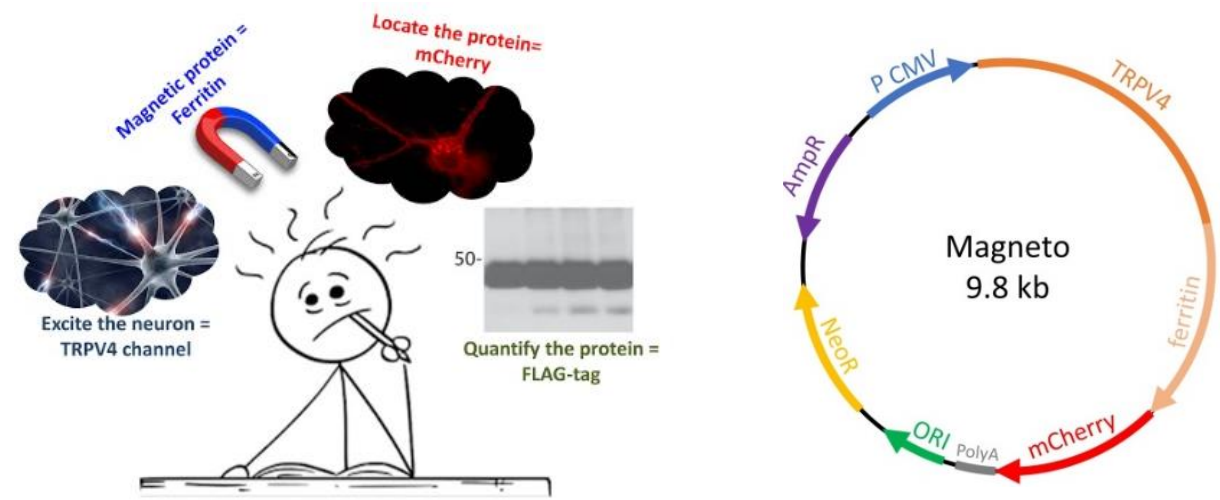

Figure 2. Magneto

plasmid design

problem where

students learned

about a plasmid

that excited

neurons with

magnets.

In a separate class, students then walked through the design steps of creating a plasmid called "Magneto" (google form), a real plasmid based off the paper by Wheeler et al. ${ }^{7}$ The google form was created to guide students through the process where explanations were provided for the students when they chose the wrong answer. Each scenario was designed to provide context on why different aspects of a vector (Figure 2) were important and when you would use them, including: origin of replication, promoter region, reporter gene, selectable marker, restriction sites, multicloning sites, initiation sequence, ribosome binding site, terminator sequence, enhancer sequence, and a protein tag.

Pre and post-module comprehension of cell culture techniques and plasmid design were assessed via canvas modules. Prior to the modules (on the same day, in a 2 hour class period), students were lectured on all of the material covered on the quizzes but were not provided time to study. After students took the pre-module assessment, no feedback was given on whether their answers were correct. The modules were then performed and the same questions were asked in the post-module assessment (taken after the module on the same day).

Cell culture assessments (multiple choice - choices were not included to conserve space):

1. What is the stage of culture where the cells have been directly isolated from the tissue and proliferated under the appropriate conditions until they occupy the available substrate?

2. Why are cell culture hoods used to culture cells?

3. Why is cell culture referred to as in vitro?

4. What $\mathrm{pH}$ do most cells grow at?

5. Why is L-glutamine an important amino acid in cell culture?

6. What is the function of phenol red?

7. Adherent cultures should be passaged at what phase?

8. To encourage cell growth, what are the conditions inside of an incubator?

9. Why is sodium bicarbonate added to cell culture media?

10. What is confluency?

A

10
8
6
4
2
0

B

10

8

6

4

2

0

Pre lab score

\section{6} 4

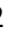

0

$-$
Cell Culture Demo

10
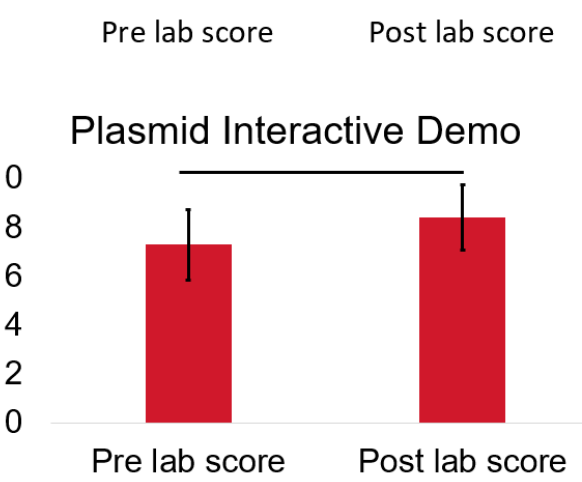

Figure 3. The interactive modules enhanced comprehension of key concepts. Canvas quizzes were used to test students on key concepts. Assessment scores (out of 10) significantly improved after the interactive: A) cell culture game ( $p<0.05$, paired t-test, $n=49$ students) and B) plasmid google form $(p<0.05$, paired t-test, $n=47$ ). Error bars represent standard deviation. 
Plasmid design assessments (multiple choice - choices were not included to conserve space):

1. What is a small circular piece of DNA (often found in bacterial cells) called?

2. You want to cut a specific region of DNA and insert your gene of interest. What is the site where you want to insert the DNA called?

3. How will you know if your gene is transfected correctly?

4. To stop the reading of your plasmid, what would you add in?

5. How do you selectively target which cells have taken up your plasmid?

6. Definition of restriction enzymes?

7. Definition of enhancer sequences?

8. Definition of ORI?

9. Definition of multicloning sites?

10. You want to use recombinant DNA technology to create large quantities of insulin. After you have replicated your plasmid in bacteria, what is the next step in obtaining a purified protein?

Results: Prior to the cell culture game the assessment average was 62\% (Figure 3). After the game, the post-module assessment improved significantly to $88 \%$. For the plasmid google form, the pre-module assessment average was $73 \%$ and improved significantly to $84 \%$ on the postmodule assessment.

Limitations: There were limitations in the design of the current study that should be improved in subsequent studies. For example, the interactive learning modules were not compared to other pedagogical techniques and therefore it is unclear if this technique conveys content knowledge better than other methods. Another limitation was that time-on-task was not controlled for. A better design would be to split up students into 2 groups (so there would be a control group). Instead of using the students themselves as the benchmark, a separate group of students could spend time watching a video/or studying notes to conclusively determine if time-on-task or active learning was responsible for the enhanced comprehension of key concepts. Finally, another possibility is that repeated exposure to the material could have reinforced concepts in these students.

Discussion: Following the passive learning techniques with an active learning module enhanced comprehension of key concepts related to cell culture and plasmid design. This was likely related to increased engagement of students in the learning process through meaningful activities that required the student to think about what they were doing. ${ }^{1}$ These preliminary results suggest that a controlled study, with a better study design to test active learning and its effect on improving learning comprehension of key concepts, is warranted. In future work a student perception survey will also be performed to compare traditional methods of teaching the concepts to the described interactive learning methods.

\section{References:}

1. Prince M. Does active learning work? A review of the research. J Eng Educ. 2004;93:223-231.

2. Lawson TJ. Active-Learning Exercises for Consumer-Behavior Courses. Teach Psychol. 1995;22:200-202.

3. Watson DL, Kessler DA, Kalla S, Kam CM and Ueki K. Active learning exercises are more motivating than quizzes for underachieving college students. Psychological Reports. 1996;78:131-134.

4. Bullard L, Felder $R$ and Raubenheimer D. AC 2008-521: EFFECTS OF ACTIVE LEARNING ON STUDENT PERFORMANCE AND RETENTION. age. 2008;13:1.

5. Townsend MAR, Moore DW, Tuck BF and Wilton KM. Self-concept and Anxiety in University Students Studying Social Science Statistics Within a Co-operative Learning Structure. Educational Psychology. 1998;18:41-54.

6. Nora LC, Westmann CA, Martins-Santana L, Alves LF, Monteiro LMO, Guazzaroni ME and Silva-Rocha R. The art of vector engineering: towards the construction of next-generation genetic tools. Microb Biotechnol. 2019;12:125-147.

7. Wheeler MA, Smith CJ, Ottolini M, Barker BS, Purohit AM, Grippo RM, Gaykema RP, Spano AJ, Beenhakker MP, Kucenas S, Patel MK, Deppmann CD and Guler AD. Genetically targeted magnetic control of the nervous system. Nat Neurosci. 2016;19:756-761. 